INDAR S. LUTHAR

R. F. REYNOLDS and

A. H. THOMPSON

B. T. Bennetr and

R. B. Potrs

T. J. Dickson

I. D. MacDonald

N. D. Gupta

DAVID LoNDON and ZVI ZIEGLER

A. RÉNYI and G. SZEKERES Sadayuki Yamamuro

K. W. Chang

JOHN D. DixoN

PAUL CONRAD

W. A. Coppel and A. Howe SADAYUKI YAMAMURO

M. J. C. BAKER

R. E. EDWARDS

R. T. WORLEY

R. T, WORLEY

J. D. GRAY

R. G. BURNS

WARREN J. WONG

Albert D. Polmmeni

Fu Cheng Hsiang

JOHN D. DIXON

JOHN COATES

I. D. MacDonald and

B. H. Neumann

N. SMYTHE

R. P. Hunter and

L. W. ANDERSON

J. M. DAY and A. D. WALlace

A. H. KLotz

A. H. KLotz

R. A. Alo and H. L. Shapiro JOSEPH BARBACK

D. G. JAMES

NeIL. W. RICKERT

John Poland

EFRAIM P. ARMENDARIZ

A. J. VAN DER POORTEN

JoHN M. BLATT

C. C. Heyde

E. Seneta

J. C. Burns

\section{FORTHCOMING PAPERS}

A note on a result of Mahler

Projective-symmetric spaces

Arrays and brooks

The extreme coverings of 4-space by spheres

Corrigendum, Another law for the 3-metabelian groups

Commutation near-rings of a group

Functions over the residue field modulo a prime

On the height of trees

A note on $d$-ideals in some near-algebras

A stability result for the linear differential equation $x^{\prime \prime}+f(t) x=0$

The Fitting subgroups of a linear solvable group

A characterization of lattice-ordered groups by their convex $L$-subgroups

Dynamical instability of linear canonical systems

A note on vector lattices

A Helly-type theorem on a sphere

Criteria for Fourier transforms

Minimum determinant of asymmetric quadratic forms

Asymmetric minima of indefinite ternary quadratic forms The summability of formal solutions of functional equations Verbal wreath products and certain product varieties of groups Finite groups with a self-centralizing subgroup of order 4

Finite solvable c-groups

On the absolute Nörlund summability of a Fourier series

Normal p-subgroups of solvable linear groups

Approximation in algebraic function fields of one variable

A third-Engel 5-group

Trivial knots with arbitrary projection

Certain homomorphisms of a compact semigroup onto a thread

Semigroups acting on continua

A note on de Sitter type solutions of Einstein's field equations Relativity, uncertainty and electrodynamics

A note on compactifications and seminormal spaces

An $M d$-class of sets indexed by a regressive function

Transitivity in integral symplectic forms

Some properties of locally compact groups

Two problems on finite groups with $\mathrm{k}$ conjugate classes

On radical extensions of rings

Transcendental entire functions mapping every algebraic number field into itself

Statistics of fragments from enzyme-induced breakup of copolymer chains

Some local limit results in fluctuation theory

On the transient behaviour of a Poisson branching process

The iterated equation of generalized axially-symmetric potential theory

I. Particular solutions

II. General solutions of Weinstein's type

III. Conjugate general solutions 


\title{
JOURNAL OF ENGINEERING MATHEMATICS
}

The "Journal of Engineering Mathematics" publishes original work in engineering science in which the mathematical method of solution is essential.

The aim of the journal is to promote the application of mathematics to engineering problems and to stress the intrinsic unity of the fundamental problems of different branches of engineering, varying from basic principles of physics and mechanics to management and computer science. Articles are only published if their bearing on engineering subjects is apparent and if the mathematical approach to the problem is essential.

It is issued quarterly (January, April, July and October) and contains about 80 pages per issue. Annual subscription rates for libraries, institutes, firms, government organizations: $\$ 16.50$ per volume (Postage included).

Special rates for individuals are available on application.

Editor-in-Chief: R. Timman. Board of editors: A. J. W. Duijvestein, P. Eijkhoff, J. W. Sieben, J. A. Sparenberg, E. van Spiegel, G. W. Veltkamp, A. I. van de Vooren, J. V. Wehausen, L. van Wijngaarden, P. J. Zandbergen, Editorial secretary: H. W. Hoogstraten, Technical University, Delft, Holland.

First issue January 1967

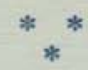

\section{INTERNATIONAL JOURNAL OF FRACTURE MECHANICS}

This journal is intended to be a medium for original theoretical or experimental contributions which provide a better understanding of the mechanics causing micro and macro fracture in various different materials, and their engineering manifestations and significance. Contributions emphasizing empirical correlations and unanalyzed experimental results, while important and necessary aspects of certain fatigue, strength and fracture analyses will normally not be encouraged, although occasional review papers in these as well as other fields are anticipated and welcomed.

The journal is issued quarterly and contains about 80 pp. per issue. Annual subscription rates for libraries, institutes, firms, government organizations: $\$ 25 .-$ (postage included). Special rates for individuals are available on application.

Editor-in-Chief: M. L. Williams, University of Utah, Salt Lake City, U.S.A. Regional Editors: G. I. Barenblatt, W. F. Brown Jr., J. Friedel, S. Gratch, A. K. Head, V. Horak, F. Kerkhof, J. R. Low Jr., T. Pelczynski, N. J. Petch, H. Rumpf, C. A. Verbraak, A. A. Wells, T. Yokobori, S. N. Zhurkov.

\author{
PUBLISHED BY P. NOORDHOFF LTD - GRONINGEN \\ THE NETHERLANDS
}

